\title{
Learning Research Methods and Processes via Sharing Experience in a BLOG
}

\author{
L. Giarré* and L. Jaccheri**
}

\begin{abstract}
The goal is to increase knowledge about different research methods that have been employed in the information technology field by supporting the information exchange, collaboration, and cooperation between researchers. We stress the importance of sharing knowledge through storytelling. Welldesigned, well-told stories can help others learn from past situations to respond more effectively in future situation. A blog is presented where $\mathbf{P h D}$ students and researchers are invited to collaborate by providing their stories, reading and commenting existing stories. This infrastructure allows researchers and $\mathrm{PhD}$ students to write the contents posing questions and finding answers on the relationship between research process and research results.
\end{abstract}

Keywords Research methods, storytelling, experience sharing, $\mathrm{PhD}$ research courses

\section{INTRODUCTION}

In this paper we present a blog aimed at describing, comparing and improving the different methods of research that have been employed in different scientific areas with special attention devoted to control. Supporting the exchange of information, collaboration, and cooperation between researchers is a way to learn research methods. The sharing units are stories written by researchers and organized in a blog. Some general definitions of basic and applied research as well as research methods and processes can be found in [15]. A research process is defined as a process whose scope is to produce some new knowledge and that in principle can take three main forms:

* Exploratory research: a new problem can be structured and identified.

* Constructive research: a (new) solution to a problem can be developed.

* Empirical research: empirical evidence on the feasibility of an existing solution to a problem can be provided.

Our main question is "what is a research method"? In definition 3. of the American Heritage Dictionary a method is defined as The procedures and techniques characteristic of a particular discipline or field of knowledge. But the existing differences in the various fields and disciplines have standardized different peculiar meaning. Understanding to this question is the main and final goal of the entire process. Writing and listening, discussing and exchanging information

\footnotetext{
* L. Giarré is with Dipartimento di Ingegneria dell'Automazione e dei Sistemi, Università di Palermo, Viale Delle Scienze, 90128 Palermo, Italy, giarre@unipa.it, ph.091-481119; Fax-091-427940

** L. Jaccheri is with Department of Information and Computer Science, Norwegian University of Science and Technology, Trondheim, Norway. letizia@idi.ntnu.no
}

has the ultimate goal of let us know and learn the answer. The learning process is the byproduct of the overall procedure.

Research methods have been studied and debated at conferences and seminars (top down approach) and between friends and colleagues (bottom up approach). Research processes are learning processes in which experienced researchers, $\mathrm{PhD}$ students, master students, and external actors, collaborate to achieve research goals. Research processes are often driven and regulated by formalized methods and procedures, see [3] for general hints.

The art of research can be learned by a combination of doing and reading research literature. Research communities rely on different research methods, depending on both the academically field and the tradition of the research institution and group. For example in Scandinavia there is a strong emphasis on empirical based research in all fields, while in Italy there is a stronger theoretical tradition.

In order to learn research methods, one possible way is to provide an infrastructure to share research experience and to look for a common language in different technological fields. A preliminary description of this activity is reported in [8].

This paper is structured as follow: Section II provides a short summary of web based infrastructures and their relationship to the research community. Section III makes explicit the goals of this work (description, application, comparison and improvement of the different methods of research). Section IV presents our blog and section V provides a preliminary analysis of the information on the blog with respect to our goals. Conclusions are given in VI.

\section{BACKGROUND}

Many Web resources in the last years have turned from simple information points to places for promoting communities. A growing number of studies describe sites that are used to support distributed communities, kept together either by common practices or shared interests. In the last years a set of principles have been put forward for the design of web sites (sometimes called portals) for supporting distributed communities. Web sites, providing basic but very effective tools for communication and information sharing together with a virtual meeting place, can successfully support community building and knowledge sharing [9]. At the same time, reported experience also points out the risk of recording information outside a relevant social context.

For example, in the field of software engineering experience factories have been suggested as a way to promote knowledge reuse among different projects [1]. However, these resources, many of which are Web based, have proved 
to be rather problematic and their success strongly depends on the capability of the supporting system of not disconnecting information the social context where this information is created and used. This is pointed out also in an extensive body of literature about community and organizational memories and within knowledge management [13].

In the control field, web-based sites and e-learning are mostly devoted to control laboratory and remote laboratory. We all have experimented in our courses the importance of learning how to control a process on a real experiments, and sharing these labs through the web is very effective to share a common engineering experience. Very little has been done in terms of distributed communities and sharing knowledge, for example, nothing can be found in one of the most used web-site [2], that is a collection of useful links, listing control groups, journals and other activities in the control fields. In a recent panel [4], some fundamental questions of our fields arose: 'What is the core of control?', or 'What is important to form good control people?'. Panel discussions at conference, round tables and meetings have been in the past the only place where the community have met and shared knowledge. Some of the web-forum present are professional ones devoted to control engineers more than to researchers. In terms of research methods and process not much is available in the systems and control area or on $\mathrm{PhD}$ courses devoted to this topic.

There are many initiatives connected to our strategic choice of focusing on research methods in other fields. As an example we refer to [6]. Here many interesting links are present, for example links to $\mathrm{PhD}$ courses on research methods. Our experience as Empirical Software Engineering researchers and supervisors for $\mathrm{PhD}$ students and our long term cooperation with industry actors tell us that, while there exist a bulk of good literature in the empirical software engineering field, cooperation within the research group, cooperation with industry, and relevance of the research problems are actual problems. Too many $\mathrm{PhD}$ students work in isolation for many years and deliver theses which are seldom read by anyone else that the thesis reviewers. We report the empirical software engineering $\mathrm{PhD}$ level course, held at both NTNU and University of Oslo since 2002, and described at [5] as a prototype. Here, a basic empirical software engineering syllabus is identified. In addition, creative methods especially thought for innovation and cooperative processes have been exploited. The process has been documented by pictures and videos available at the Empse WEB site.

Sharing experiences through stories is emerging in various professions as a powerful way to exchange and consolidate knowledge as analyzed in [11]. The use of storytelling is a way of connecting, knowing, and a way to facilitate the processes of nursing education, practice, and research, [10].

\section{THE GOALS OF OUR WORK}

Given a set of different methods of research that have been employed in our field, our goals with respect to research methods are:
1) Description

2) Application

3) Comparison

4) Improvement.

We are genuine interested in learning more about research processes and to share our knowledge with our $\mathrm{PhD}$ students and colleagues. We aim at investigating the analogies between our fields (Software Engineering and Systems and Control) and by talking about similarities and differences we learn a lot.

What would I do if I started a $\mathrm{PhD}$ now? If I would do exactly the same, it means that I have not learned anything. What do I tell to a new PhD student? Learning can be done by supporting information exchange, collaboration, and cooperation between researchers. We are looking for a common language in different fields and we would like to find analogies or differences among technological fields The topics under investigation are questions related to researchers background, their research methods and processes. We invite other people to participate. The incentive is the desire of learning that motivates any researchers:

- Learning what? Learning the different approaches to research.

- Learning how? Learning by sharing their experience and reading stories.

- Learning why? Learning is the base of investigation and research.

Moreover, we aim at organizing common events where people can meet face to face and at getting funding to sponsor the events. Our work will contribute to the research community by providing a dialog forum, which will be WEB based but also supported by face to face initiatives.

\section{OUR Proposal: the Researcher Blog}

We stress the importance of sharing knowledge through storytelling. Well-designed, well-told stories can help others learn from past situations to respond more effectively in future situation. Such stories come in different forms and with a variety of labels e.g. cases, anecdotes, examples, histories or simply experiences.

We see this blog as a blank paper where people write the contents posing questions and finding answers, with their stories. This is a koiné, a meeting point where researchers share their view about research and talking with the others, learn and teach research processes. The idea is that we do not want answer to 'specific' questions, but we are eager for questions and suggestions.

We propose our way to support the research community by establishing a researcher blog [7].

The term blog is a shortened form of the coined word weblog. Although a blog is in essence an online diary, the simplicity of the online environment has meant that its use is limited only by the imagination of its users. According to [12], blogs are not only devoted to documentation of lives, or to express some felt emotions but also to articulate ideas through writing and to form and maintain community forum. 
Our blog is a community forum that is open to different research methods and personal research experiences. It aims at investigation of the relationship between research process and research results.

Our infrastructure has started in a bottom up fashion and we aim to expand it both bottom up (by involving local and disperse colleagues) and and top down (by applying for founding and participation to conferences). We have contacted local PhD students and researchers. We are in the process of taking contact with different research communities, and try to inform researchers working both in industries and universities/research centers. Storytelling is used as the main instrument for our project to investigate the above topics. We publish research stories and by our example we want to stimulate other researchers to share their experience and give us feedback's.

Our first version of the Blog is supported by Blogger.com. The choice is pragmatic. We need to recruit people, locally and globally, to populate the forum and exploit the dissemination. The selected and collected stories, with their comments will be the basis for the design of a better Web support.

Researchers and $\mathrm{PhD}$ students from different areas in the Information technology fields (Control, Telecommunication, Computer Science etc.) and of various nationality have been contacted to contribute to it. At the time of writing, the Blog is moderated, but comments are allowed to everyone. We are discussing and experimenting alternative cooperation models, like that of allowing every interested user to submit their stories.

As suggested in [11], three aspects are essential:

The story-crafting:

Effective knowledge-sharing stories are intentionally crafted for the audience. A good knowledge sharing story should be both simple and accessible.

The story-telling:

The impact of a story will depend on its telling who tells the story and whether it is shared in an oral or written form.

The story-listening:

It is critical for storytellers to monitor the reception of their stories. The audience is engaged in creating knowledge while listening, so storytellers check how this knowledge is being constructed.

In order to facilitate the story-telling phase a set of questions have been set up. The teller can either contribute by its own story or answering to the following questions.

Questions:

These questions can be used to discuss and reflect about research methods.

1) Research Methods

a. Can you describe the main steps in the research method that guides your research process?

b. Is your research method inspired by a well known research method? If yes, which? c. Would you classify your research method as Exploratory research (a new problem can be structured and identified); Constructive research (a new solution to a problem can be developed); Empirical research: empirical evidence on the feasibility of an existing solution to a problem can be provided.

2) Choice of the Topic: Which factors influence the choice of your topic?

a. the funding procedure?

b. the discussions at meetings and conferences?

c. the exchange of ideas with colleagues?

d. the reading of literature?

e. some genuine and inner interest?

f. advisor suggestions?

3) How does cooperation with co-authors or with advisors evolve during:

a. the phase of writing the papers?

b. the phase of discussions and analysis?

c. the phase of testing or simulations?

d. literature review

e. other

In order to implement the story-listening phase, an improvement mechanism need to be constructed. It is important to associate other aspects to the stories that mainly intended to promote the liveness of the community. They can also be used to provide feedback to the authors of the stories and to the content manager. Some simple examples are provided below.

Send this story to a colleague. This is implemented to support knowledge exchange within the community, possibly also acting as an indirect way to involve external participants.

Rating, e.g. (Do you find this story interesting? Rate it from [1-5]). The mechanism implemented by this service can provide an indication about the relevance of a specific topic. For the other community member is a low-cost form of participation, that can hopefully evolve into more direct forms of involvement. Also, showing the results of the rating (or voting, see next point) can promote the feeling of an alive community.

Comment Add comments to the stories.

The first two services represent different forms of very peripheral participation. However, they are easy to use and can trigger the participation of newcomers and people lacking the time or confidence for a more open participation. Gradually users can move to a more active role within the community thanks to the other services that support various form of communication among community members.

Actually, the only available service is Comment a story.

\section{AnAlysis AND Discussion}

At the time of writing this paper, the blog has 21 posts. In Table I the numbered list of the actual posts with their title and author is reported.

The simplest way to analyze the stories on our blog is to read them, comment them, and write new stories on the blog itself. 


\begin{tabular}{|c|c|c|c|}
\hline Number & date & Title & Author \\
\hline 21 & $8 / 24 / 2005$ & $\begin{array}{l}\text { QUESTIONS (to } \\
\text { facilitate story-tellers) }\end{array}$ & L. Jaccheri \\
\hline 20 & $4 / 29 / 2005$ & My story & A Bellini \\
\hline 19 & 4/28/2005 & $\begin{array}{l}\text { Wikipedia } \\
\text { Research, methods, } \\
\text { and processes }\end{array}$ & L.Jaccheri \\
\hline 18 & $4 / 20 / 2005$ & ICIE 2005 & L. Giarré \\
\hline 17 & $4 / 18 / 2005$ & $\begin{array}{l}\text { Two days workshop } \\
\text { in memory of } \\
\text { Giovanni }\end{array}$ & L. Giarré \\
\hline 16 & $3 / 04 / 2005$ & $\begin{array}{ll}\text { about } & \text { software } \\
\text { engineering } & \end{array}$ & L. Jaccheri \\
\hline 15 & $2 / 25 / 2005$ & $\begin{array}{l}\text { From my other blog } \\
\text { on art+IT }\end{array}$ & L. Jaccheri \\
\hline 14 & $2 / 25 / 2005$ & $\begin{array}{l}\text { ICMTL 9-11 march } \\
2005\end{array}$ & L. Giarré \\
\hline 13 & $2 / 14 / 2005$ & Inside post & L. Jaccheri \\
\hline 12 & $2 / 10 / 2005$ & Some comments & P. Falugi \\
\hline 11 & $1 / 31 / 2005$ & 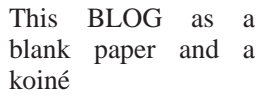 & L.Giarré \\
\hline 10 & $1 / 27 / 2005$ & $\begin{array}{l}\text { Some literature on } \\
\text { research methods }\end{array}$ & L. Jaccheri \\
\hline 9 & $1 / 25 / 2005$ & An interesting paper & L. Jaccheri \\
\hline 8 & $1 / 4 / 2005$ & Being a researcher & D. Angeli \\
\hline 7 & $1 / 3 / 2005$ & $\begin{array}{l}\text { Chatting over this } \\
\text { blog }\end{array}$ & L.Giarré and $\mathrm{F}$. \\
\hline 6 & $12 / 31 / 2004$ & The why dimension & L.Jaccheri \\
\hline 5 & $12 / 21 / 2004$ & $\begin{array}{l}\text { Questions } r \text { from } \\
\text { Doyle's panel at } \\
\text { CDC }\end{array}$ & L. Giarré \\
\hline 4 & $12 / 21 / 2004$ & Talking at CDC & $\begin{array}{l}\text { L. Giarré and M. } \\
\text { Dahleh }\end{array}$ \\
\hline 3 & $12 / 7 / 2004$ & $\begin{array}{l}\text { The origin of the } \\
\text { present blog }\end{array}$ & L. Giarré \\
\hline 2 & $12 / 2 / 2004$ & The end of E3 & L. Jaccheri \\
\hline 1 & $12 / 2 / 2004$ & $\begin{array}{l}\text { The beginning of the } \\
\text { E3 project }\end{array}$ & L. Jaccheri \\
\hline
\end{tabular}

TABLE I

Actual Posting In the Blog

To provide a formal analysis of the information present on the blog, one way is to use our own goals as defined at the beginning of section III and discuss if and how each post address description, application, comparison or improvement of research methods. The idea is to go through each contribution and relate it to the research method it discusses. The purpose of the discussion can be either description of one method or the application of one specific method, comparisons of two or more, or description of improvement of existing methods.

In Table II this preliminary analysis is reported.

Some of the stories received comments. The comments are the interactive and collaborative part of the blog. In Table II, we report some of them (labeled with "-comment").

Various strategies are available within qualitative research

\begin{tabular}{|c|c|c|}
\hline Number & Text & goal \\
\hline 20 & $\begin{array}{l}\text { In my field now, since we are develop- } \\
\text { ing a simulation code, we first start by } \\
\text { developing the necessary equation (con- } \\
\text { stitutive etc.), implementing them in a } \\
\text { numerical code and then comparing the } \\
\text { obtained solution with analytical cases } \\
\text { as well as with experimental results. In } \\
\text { conclusion, we use empirical, analytical } \\
\text { and implementation methodology. }\end{array}$ & comparison \\
\hline 10 & $\begin{array}{l}\text { This is a collection of papers, links } \\
\text { and web-sites on research methods }\end{array}$ & description \\
\hline 8 & $\begin{array}{l}\text { How do I choose my topics. For as } \\
\text { obvious as it may sound, one way is } \\
\text { to start with a natural mathematical } \\
\text { question }\end{array}$ & description \\
\hline 4 & $\begin{array}{l}\text { Munzer loved the abstraction and } \\
\text { pedagogy of linear algebra and found } \\
\text { that system theory and control poses } \\
\text { similar attributes. }\end{array}$ & comparison \\
\hline 3 & $\begin{array}{l}\text { I still believe that what you should } \\
\text { always ask to yourself and let the } \\
\text { young ask to themselves is not 'how } \\
\text { many papers did i publish last year?' } \\
\text { but 'did i learn something interesting?' } \\
\text { 'did i understand what i was doing?' }\end{array}$ & description \\
\hline 11-comment & $\begin{array}{l}\text { Finding a question is more important } \\
\text { sometimes than finding the answer. }\end{array}$ & description \\
\hline 8-comment & $\begin{array}{l}\text { The author discusses how the start of } \\
\text { a research process looks like, how he } \\
\text { gets the idea. I would like to know } \\
\text { what he does, after and before getting } \\
\text { the idea }\end{array}$ & description \\
\hline 9-comment & $\begin{array}{l}\text { research as freedom in 1) choose } \\
\text { a topic; 2) develop ideas } 3 \text { ) explore } \\
\text { new territories : nice but a bit too utopic }\end{array}$ & application \\
\hline 5-comment & $\begin{array}{l}\text { I am curious about the question teach } \\
\text { to form good control people. Here in } \\
\text { Scandinavia, my students would protest. } \\
\text { if we used the terms: teach, form, good }\end{array}$ & comparison \\
\hline
\end{tabular}

TABLE II

ANALYSIS OF SELECTED STORIES

to protect against bias and enhance the reliability of findings. In [14], qualitative research methods have been described. In many disciplines, qualitative methods are used to handle the complexity of issues involving human behavior. Analytical tools based on grounded theory for qualitative research ([17], [18]) is at the moment under development.

\section{CONCLUSIONS AND FURTHER WORK}

We have presented a blog that we (the authors) use to share research experience between us and our colleagues. The research process we have been following in this work, encompasses three steps (goal definition, blog design and implementation, and analysis). First there is the definition of four goals that are description, application, comparison, and improvement of research methods. To achieve these, we have designed and implemented the blog and a preliminary qualitative analysis that maps blog stories to goals.

To transform our blog into a web forum it is crucial to 
recruit students and researchers that will act as both storylisteners and story-tellers. More publicity must be carried out and face to face explanations need to be implemented so that the blog is populated and kept alive.

Some steps of the improvement mechanism need to be implemented.

We need to progress with our blog to learn how to involve other people and getting funds to promote the blog and possibly transforming it in a an engineered product.

There is a long way to go to improve our blog in a way it becomes an attractive place for researchers to visit and contribute to. We see this paper as a step to make this blog known to other researchers. We are eager to get constructive criticism to our proposal in a way we will be able to guide people to reflect about their research processes and the associated methods and to be wiling to share this knowledge with us and with each other.

\section{REFERENCES}

[1] Basili, V., Caldiera, G. \& Rombach, D., Encyclopedia of Software Engineering. Wiley: Berlin and New York, 1994.

[2] Control Engineering Virtual Library, Department of Engineering, Cambridge University, http://wwwcontrol.eng.cam.ac.uk/extras/Virtual_Library/_Control_VL.html, last accessed August 2005.

[3] Marie desJardins. "How to be a Good Graduate Student" (.html catalogs), Purdue University, IN, USA, 1994 (taken from DIF8916), http://www.cs.indiana.edu/how.2b/how.2b.html, last accessed August 2005.

[4] Plenary Panel Discussion Challenges and Opportunities for the Future of Control Panelist: Doyle, John C.; Cassandras, Christos G.; Carlson, Jean; Kumar, P. R.; Leonard, Naomi Ehrich; Mabuchi, Hideo. 43rd IEEE Conference on Decision and Control, Nassau, The Bahamas, 2004.

[5] L. Jaccheri. Software Empirical software engineering Course.http://www.idi.ntnu.no/ letizia/empse2005, 2005, last acessed August 2005.

[6] R. Conradi. Some hints for paper writing and searching, with further links. http://www.idi.ntnu.no/grupper/su/publ/ese/esepublications.html, last accessed August 2005.

[7] Giarré L. and L. Jaccheri. http://researcherblog.blogspot.com/, Last accessed August 2005.

[8] L. Giarré and L. Jaccheri. Learning Research Methods via Experience Sharing, International Conference on Methods and Technologies for Learning, WIT press, Palermo 2005.

[9] Girgensohn, A. \& A., L., Social navigation: Making web sites be places for social interaction. ACM conference on Computer supported cooperative work, ACM Press, pp. 136 - 145, 2002.

[10] Kelly, B., Storytelling: a way of connecting. Nursing Connections, Vol.8, No. 4, pp. 5-11, 1995.

[11] Sole, D. \& Wilson, D., Storytelling in organizations: The power and the traps using stories to share knowledge in organizations. LILA, Harvard, Graduate School of Education, 2002.

[12] B. A. Nardi, D. J. Schiano, M. Gumbrecht and L. Swartz. Why we blog. Communications of the ACM, Vol. 47, No. 12, 2004.

[13] G. Schwartz, S.D., Divitini, M. \& Brasethvik, T., On knowledge management in the internet age. Internet-based Knowledge Management and Organizational Memories, Hershey, USA, 2000.

[14] Seaman, Carolyn B., Qualitative Methods in Empirical Studies of Software Engineering, IEEE Transactions on Software Engineering, Vol. 25, No. 4, pp.557-572, 1999.

[15] Research From Wikipedia: The Free Encyclopedia at http://en.wikipedia.org/wiki/Research, Last accessed August 2005.

[16] Claes Wohlin, Per Runeson, Martin Hőst, Magnus C. Ohlsson, Bjốn Regnell and Anders Wesslén,Experimentation in Software Engineering: An Introduction, Kleuwer Academic Publishers, ISBN 0-79238682-5, 2000.

[17] Strauss, A. and Corbin, J. Basics of qualitative research: Grounded theory procedures and techniques., London: Sage, 1990.
[18] N. R. Pandit. "The Creation of Theory: A Recent Application of the Grounded Theory Method", The Qualitative Report,Volume 2, Number 4, December, 1996 (http://www.nova.edu/ssss/QR/QR2-4/pandit.html). Last accessed August 2005. 